
Address: 54/1 Peremoha Ave, 03057, Kyiv, Ukraine

E-mail: tanya_kostylova@ukr.net

\title{
PECULIAR FEATURES OF ATTAINING THE CERA DESIGNATION IN CANADA
}

\begin{abstract}
The article sets out peculiar features of attaining the CERA credential from the Canadian Institute of Actuaries. The analysis results show that there are scores of ways available to candidates perusing the aim of becoming a CERA. There have been singled out the main models following which it is possible to get the designation which is administered by the following professional bodies: the pathways proposed by the Institute and Faculty of Actuaries, the German Society of Actuaries and European Actuarial Academy, the Netherlands and France exam systems, and finally the examinations and modules offered by the SOA. Since there are no examinations and modules leading to the designation administered solely by the CIA, the research is basically focused on the analysis of the standards laid down by the CAS and SOA which are the Institute's closest partners offering the requirements completion of which results in attaining not just the CERA, but also the ACIA and FCIA credentials. Having analyzed the SOA'S CERA examination systems, we have figured out that for candidates willing to become CERAs there are only two ERM specific activities: the ERM exam and module. We may conclude that there is a considerable overlap between the two, only the exam section dedicated to extensions being different. The CAS system is organized on the basis of cooperation with the Institute and Faculty of Actuaries meaning that on the pathway to the designation awarded by the CAS candidates have to complete the Risk Management Specialist Technical Exam which is commonly abbreviated to ST-9. The second ERM specific requirement is the completion of the Enterprise Risk Management and Modeling Seminar. A two-fold nature of the CERA requirements in the CAS case is utilized to a more efficient extent as it adds an interactive component and an opportunity to exchange experience with the actuarial practitioners working in the field of ERM.

Keywords: CERA, actuary, Canada, CIA, SOA, CAS, ERM exam and module, ST-9 exam, Enterprise Risk Management and Modeling Seminar.

\section{INTRODUCTION}

Taking into account the fact that the actuarial profession is well-equipped with methods and tools for risk modeling and management, calculating such measures as, for instance, mortality rates or insurance rates and pension contributions, the rationale behind applying similar practice to nonfinancial fields is evident. Thus, Enterprise Risk Management (ERM) has expectedly become the branch where actuarial knowledge and skills are an essential component of legal entities' financial solvency. ERM implies hazards detection, their monitoring and management with the aim of boosting stakeholders' earnings. In developed countries these functions are currently performed by qualified specialists that have acquired the CERA (Chartered Enterprise Risk Actuary) designation. Unfortunately, for the time being there are no such professionals in Ukraine. But with transformational
\end{abstract}


processes to market economy in our country, resulting market volatility with its ups and downs, when financial threats are all around, Ukrainian labour market is definitely in need of effective risk managers. From this perspective, the analysis of foreign successful experience of Chartered Enterprise Risk Actuaries education and credentialing seems to be of great importance as it might foster both the development of ERM in Ukraine and be a factor of our education system becoming a part of worldwide cooperation bringing our professionals' training practice closer to the world standards.

\section{THE AIM OF THE STUDY}

Thus, the aim of this paper is to analyze the pathways available to Canadian actuaries to the CERA credential by comparing the SOA (Society of Actuaries) and CAS (Casualty Actuarial Society) requirements for attaining the designation.

\section{THEORETICAL FRAMEWORK AND RESEARCH METHODS}

Since the CERA qualification is a relatively new credential, it hasn't been the research subject in psychological and pedagogical fields of Ukraine yet. Peculiar features of becoming a CERA so far were only in the scope of foreign actuarial professionals' scientific interests. Thus, the theoretical framework of our research is mostly composed of regulatory documents, guidelines and professional exams syllabi of the world leading actuarial professional bodies and associations: the CERA Global Association (CGA), Canadian institute of Actuaries (CIA), SOA and CAS. Besides, the papers by Steve Eadie and Frank Sabatini (2014), Virginia Arlington (2009), Francis P. Sabatini (2012) were inspiring and of use to form a clearer picture of what it takes to become a CERA. The research methods are the analysis and synthesis of pedagogical scientific knowledge, comparative pedagogical analysis, classification of forms and approaches.

\section{RESULTS}

The qualification was first introduced in November 2009, when the group of actuarial professional bodies made a deal to cooperate with the aim of laying down the standards for a brand new designation in risk management - Chartered Enterprise Risk Actuary. All the elaborations have been reflected in the Global CERA Treaty (2009) which includes among other things qualification requirements and the reliable education quality assurance system. The control over following elaborated standards is taken by the Global CERA Association, the main goal of which is similar to the IAA and CIA and lies in the following: to elaborate rigorous professional standards; to promote the CERA designation around the world; to present risk management as a perspective field where actuarial competencies are in demand and to illustrate how risk management might benefit from actuarial skills and knowledge application. (How to become a Member Association (an Acceding Party) to the CERA Treaty, 2009).

It is also worth noting that within the Association and among its member states the CERA designation is treated as the most complex and reliable qualification that exists at present to meet the needs of threats management.

As it is the case with all the actuarial credentials, in the world practice there is no unified approach to attaining the CERA designation. In fact, each professional body being the member of the Global CERA Association follows one of the following pathways:

- Completion of ST-9 exam and the one-day seminar (the pathway is administered by the Institute and Faculty of Actuaries based in the UK and is followed by eight Member Associations located in Great Britain, the USA, South Africa, Australia, China, Japan, India and Israel; 
- Six modules, exams and seminars administered by the German Society of Actuaries and European Actuarial Academy. The latter offers the same set of requirements, but in English. The pathway is followed by Sweden, Germany, Switzerland and Denmark;

- The Netherlands' exam system (three exams, an interview based on students' scientific research and four four-day seminars);

- The French system (157 hours of education courses administered by the Institute of Risk Management and the requirement to prepare a written report);

- The way offered by the SOA followed by the USA and Canada (How to become a CERA, 2015).

The CIA which is the voice of the actuarial profession in Canada does not have its own examination system. But at the same time it has the status of an Award Signature which implies the right to award the treaty designation. Thus, it might seem to be a controversy which is effectively solved by giving Canadian actuaries several options: either to choose the CAS approach or the SOA system. Since the latter is more diverse and complicated we are going to concentrate on it first.

In order to obtain the CERA designation from the SOA, a candidate has first to sit for a number of the preliminary exams and complete other requirements leading to the Associate of Society of Actuaries designation (ASA). It includes Validation by educational experience in Mathematical Statistics, Economics, Accounting and Finance, Fundamentals of Actuarial practice e-learning course, Associateship professionalism course and the exams in Probability, Financial Math, Investment and Financial markets, Short-term Actuarial Mathematics, Statistics and Risk Modeling, Enterprise Risk Management Module and Exam (Chartered Enterprise Risk Analyst (CERA), 2018). All the above-listed requirements are compulsory for all actuaries regardless of their specialty track, the only exception being the Enterprise Risk Management Module and Exam.

Since there are only two peculiar ERM disciplines, let us now focus on what they imply. So, the Enterprise Risk Management Module is comprised of nine sections that except for module introduction and end-of-module concluding section include the following subtopics: Enterprise Risk Management as a Separate Discipline; Developing and Evaluating an ERM Framework; Regulation for Risk Management; Definition, Identification and Evaluation of Operational Risks; Collecting and Validating Data; Tools for Measuring and Assessing Risks; Economic Capital as an Enterprise Risk Management Tool; ERM in Strategic Planning (Enterprise Risk Management (ERM) Module, 2016). As we may infer from the module content analysis, it is aimed at equipping candidates with both fundamental (regulatory requirements) and application-oriented knowledge (risk measurement and managing) to dealing with risk. Such an approach contributes to giving a full picture of risks that most companies face operating in a complex business environment.

The Enterprise Risk Management Exam (2018) is divided into two parts. The first section is compulsory for all candidates and comprises the following five topics: Risk Categories and Identification, Risk Quantification and Metrics, Risk Management Approaches: tools and techniques, Economic capital management. The second section is based upon readings which students are supposed to cover according to the chosen extension. The students' extensions options are Retirement Benefits, Individual Life and Annuities, Group and Health, Investment, General Insurance, General Corporate ERM. The essential component of the second part is a case study. As we might notice, the proposed extensions are identical to the specialty tracks required to complete the FSA designation, making the ERM exam more field-specific and serving as a perfectly good reason for the 
opportunity to choose the ERM exam instead of one of the FSA requirements which we are going to be considered in more detail further in the paper.

In order to meet the demand for highly qualified risk managers from employers and with the aim of making the process of attaining the CERA credential easier and more compatible with what fellowship specialty track implies, the SOA has changed its syllabus respectively. Thus, effective from 2013 there are two options available for candidates at present: to complete the requirements of the chosen track which results in FSA designation only or candidates may also opt for earning a CERA while on the pathway to FSA that results in attaining both credentials. In this case, instead of sitting for the two-hour specialty exam or one of modules there is an opportunity to pass the ERM Exam or ERM module. How it works by tracks is illustrated with the table below.

Table 1

Optional ERM pathways available to FSA candidates resulting in either the CERA and FSA credentials or the FSA designation only*

\begin{tabular}{|c|c|c|}
\hline Track & Exam/Module for FSA & $\begin{array}{l}\text { Exam/Module for FSA } \\
\text { and CERA }\end{array}$ \\
\hline $\begin{array}{l}\text { Quantitative Finance } \\
\text { and Investment }\end{array}$ & $\begin{array}{l}\text { Investment Risk Management } \\
\text { Exam }\end{array}$ & \multirow{3}{*}{ ERM Exam } \\
\hline Individual Life and Annuities & Life Risk Management Exam & \\
\hline Retirement Benefits & $\begin{array}{l}\text { Retirement Plan Investment } \\
\text { and Risk Management Exam }\end{array}$ & \\
\hline Group and Health & $\begin{array}{l}\text { Health Foundations Module } \\
\text { Group and Health Specialty Exam }\end{array}$ & $\begin{array}{l}\text { ERM module } \\
\text { ERM Exam }\end{array}$ \\
\hline General Insurance track & $\begin{array}{l}\text { Advanced Topics in General } \\
\text { Insurance Exam }\end{array}$ & ERM Exam \\
\hline Corporate Finance and ERM & \multicolumn{2}{|c|}{$\begin{array}{l}\text { CERA is automatically rewarded upon the completion of all the } \\
\text { CFE requirements }\end{array}$} \\
\hline
\end{tabular}

*compiled by the author on the basis of the information on the pathways available on the SOA's website (2018)

In contrast to the SOA, the CAS does not administer its own CERA examination system. To get the CERA designation a candidate has to pass Exam 7 (Estimation of Policy Liabilities, Insurance Company Valuation, and Enterprise Risk Management) and Exam 9 (Financial Risk and Rate of Return) which are one of the requirements to attain the FCAS designation. In addition, a candidate must have credit for Exam ST9 (Enterprise Risk Management Specialist Technical Exam) administered by the Institute and Faculty of Actuaries, the UK, and attend The Enterprise Risk Management and Modeling Seminar (Credential Requirements, 2018). As we may easily conclude, similar to the SOA, there are two risk management specific requirements for candidates willing to get credentialed as CERAs by the CAS, and there is only one activity which is directly organized by the CAS. Let's have a look at the latter in more detail.

The seminar (2018) is aimed at: candidates' preparation to apply risk management tools and techniques to business environment by presenting real-life approaches that are used by organizations to manage hazards; increasing candidates' awareness of how ERM works in practice through lectures, case-studies and business plays; informing candidates about peculiarities of ST-9 exam sitting. 
All activities that candidates are involved in are of an interactive nature being aimed at meeting the above mentioned objectives. Participants are expected to work in teams doing technical exercises. It will be also required to present their approaches to dealing with various issues offered to candidates in the form of the four mini-cases. As a part of the seminar, all strategic decisions regarding risk and capital management are expected to be justified based on technical actuarial expertise. Besides, the course will also have an interdisciplinary component integrating actuarial science with financial economics. It enables participants to consider risk and capital management issues from a new perspective. And, of course, as it is the case with almost every designation requirement, candidates will have to work with laptops, more specifically economic capital model output will be provided to participants prior to the seminar. As for ST9 preparation, during the seminar candidates will be given some assistance in terms of typical exam questions, the exam protocol and the analysis of the examiners' reports.

The number of attendees is limited to up to 20 participants. All registration is done online on the CAS website, and it is in candidates' best interests to go through it at the earliest, as the choice is made on a first registered, first accepted basis.

ST-9 exam (2017) is aimed at instilling in candidates the key concepts, methods, tools and techniques of risk management and modeling. In order to complete the exam candidates have to master the following topics: ERM Concept and Framework, Application of ERM, Risk Categories and Classification, Risk Aggregation and Modeling, Measurement and Assessment of different Risk Types, ERM Tools and Techniques, Capital Management.

It is also worth noting that in order to attain the CERA designation from the Canadian Institute of actuaries merely passing the required exam and modules is not enough. A candidate must be a Fellow, Associate or Affiliate of the Institute. However, if a candidate is already a CERA holder, there is the transfer policy under which it is possible to transfer supervision from the current professional body to the CIA (What is CERA? 2017). In both cases it is required to complete and submit the application form.

\section{CONCLUSIONS}

Having compared the syllabi of the SOA's ERM Exam and ST-9 exam jointly sponsored by The CAS and IFoA, we may draw a conclusion that applicable to the first part of the former there is a considerable overlap between these activities. The same is true for the SOA's ERM module which offers almost the same content, but with more emphasis given to the role of ERM in strategic planning, actuarial data issues and operational risks. Such similarities result from the rigorous regulations imposed on award signatures and accredited education providers by the CERA Global Association set out in the CERA Global Treaty on key competencies that candidates have to acquire on completion of the long examination process leading to becoming a CERA. Thus, the content is highly standardized and harmonized.

Besides, we believe that the CAS approach seems to be more efficient as the two ERM specific requirements engage participants into different types of activities: the seminar is more interactive and apart from concentrating on technical knowledge, it presents a good opportunity to bounce ideas around between actuarial professionals and obtain some sort of hands-on experience, while ST-9 exam implies lots of self-study working on the recommended list of the required readings. The SOA system is not such a broad spectrum. The candidates go over nearly the same material completing the ERM module and then covering the first part of the ERM exam. The following division of the core readings into specialty tracks is dictated by the opportunity to attain the CERA 
credential while on the pathway to FSA. There is also one case study included into the extension specific portion of the ERM exam, but it is solely about a hypothetical organization. There is not any interactive component or best practice.

We may also say that the education requirements to aspiring CERAs are based upon the complex and consistent curriculum enabling to combine actuarial science with the traditional ERM approaches making the CERA credential the most comprehensive ERM qualification to date.

Perspectives for further research are possible ways in which the Canadian experience of cooperation with the SOA and CAS might be applied to the theory and practice of ERM specialists' professional training to satisfy the needs of the domestic market for competent professionals in this field.

\section{REFERENCES}

1. Arlington, V. (2009). CERA: treaty launches new risk management credential globally. Casualty Actuarial Society. Retrieved from http://www.casact.org/media/index. cfm?fa $=$ view Article \&articleID=1058\&CFID $=21878014 \&$ CFTOKEN=39384776.

2. Canadian Institute of Actuaries. (2017). What is CERA? Retrieved from http://www.cia-ica.ca/membership/cera.

3. Casualty Actuarial Society. (2018). Credential requirements. Retrieved from http://www.casact.org/cera/.

4. Casualty Actuarial Society. (2018). Enterprise risk management and modeling seminar for CERA qualification. Retrieved from http://www.casact.org/cera/index.cfm?fa= seminar.

5. CERA Global Association. (2009). Global enterprise risk management designation recognition treaty. London: CERA.

6. CERA Global Association. (2009). How to become a Member Association (an Acceding Party) to the CERA Treaty. Retrieved from http://cera.unicorn.cloud.ec/ sites/default/files/docs/Become-a-CERA-Treaty-member-final.pdf.

7. CERA Global Association. (2015). How to become a CERA. Retrieved from http://cera.unicorn.cloud.ec/sites/default/files/docs/At_a_glance_routes_to_CERA.pdf.

8. Eadie, S., \& Sabatini, F. (2014). Global CERA: an international success story. The Actuary magazine, 11 (1), 36-37.

9. Institute and Faculty of Actuaries. (2017). Subject ST9 enterprise risk management. London: Institute and Faculty of Actuaries.

10. Sabatini, F. P. (2012). Global CERA credential celebrates three-year anniversary. The Actuary magazine, 9 (5), 26-27.

11. Society of Actuaries. (2018). Chartered enterprise risk analyst (CERA). Retrieved from https://www.soa.org/Education/Exam-Req/edu-cera-req.aspx.

12. Society of Actuaries. (2016). Enterprise risk management 3.0 module objectives. Illinois: Society of Actuaries.

13. Society of Actuaries. (2018). ERM - Enterprise Risk Management Exam. Illinois: Society of Actuaries.

14. Society of Actuaries. (2018). Follow one pathway to earn both an FSA and CERA. Retrieved from https://www.soa.org/Education/Exam-Req/edu-one-pathway-earnfsa-cera.aspx. 